\title{
How do candidates' looks affect their election chances?
}

\section{Looks matter and can tip the scales between the right and left}

Keywords: beauty, elections, political candidates, beauty premium

\section{ELEVATOR PITCH}

Good-looking political candidates win more votes around the world. This holds for both male and female candidates. Candidate appearance may be especially important for uninformed voters, as it is easy to observe. Voters may favor good-looking candidates because they expect them to be more competent or persuasive, but it can also be that voters simply enjoy laying their eyes on beautiful politicians. As politicians on the right have been deemed more attractive in Europe, the US, and Australia, the importance of beauty in politics favors conservative parties. A related finding is that voters use beauty as a cue for conservatism.

\section{KEY FINDINGS}

\section{Pros}

$\oplus$ Candidate appearance is easily available for uninformed voters.

(- There is no gender difference in how voters reward beauty of male and female candidates; therefore, there is no evidence on gender discrimination in terms of how beauty is rewarded.

- Voters can, to a certain extent, infer candidate ideology from appearance by using beauty as a cue for conservatism.

๑ Even if well-informed voters do not rely on beauty to guide their voting behavior, less informed voters can and do draw inferences about ideology from it.

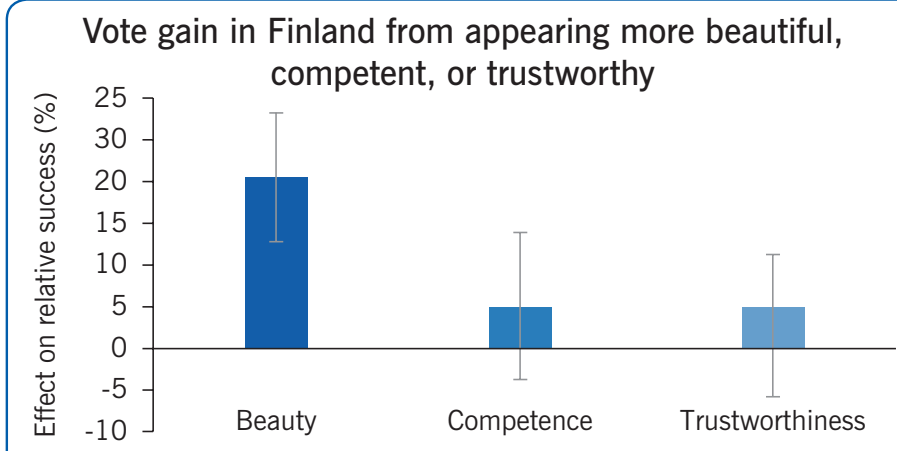

Note: Effects calculated among non-incumbent parliamentary candidates in Finland measuring vote gains of a one-standard deviation increase as a percentage of the average number of votes for all non-incumbent candidates on the same list. Results are presented with 95\% confidence intervals.

Source: [1].
I Z A World of Labor-

\section{Cons}

- The beauty premium may discourage competent but unattractive people from entering politics.

- Uninformed voters can be persuaded by good looks, and may, as a result, vote against their own interests.

- Empirical results do not imply that political parties should replace their less photogenic established politicians with good-looking novices to maximize their electoral success.

- Voters associate beauty with competence, so even the choice of voters who think that they vote for the more competent-looking candidate may be driven by beauty differences.

\section{AUTHOR'S MAIN MESSAGE}

Political candidates who look more attractive or competent have been shown to have an electoral advantage across the world, in line with a general beauty premium in the labor market. Most convincingly, beauty ratings of candidates by foreigners, who don't know anything about those running for office, predict electoral success. From a democratic perspective, recognizing various behavioral biases is valuable. Voters who become aware of a beauty premium in politics can pause for a moment to reflect on the proper role of looks for their voting decision. 


\section{MOTIVATION}

Political candidates who look more attractive or competent have an electoral advantage around the world [2]. This affects political competition both within and between parties. In addition to influencing individual races, the beauty premium in politics affects incentives to enter politics, encouraging entry by the good-looking and discouraging those who are less attractive. Even more dramatically, the beauty premium in politics may put different parties at an advantage or disadvantage, depending on the appearance of their politicians. In this way, it can influence implemented policies. Looking good helps both male and female politicians, and the effect is present in both local and national politics [1]. Politicians representing political parties on the right are, on average, more beautiful than politicians representing political parties on the left in Europe, the US, and Australia, thus giving conservative parties an electoral advantage [3]. Such a beauty gap between politicians on the left and on the right can arguably be explained by a beauty premium in the labor market: As good-looking people earn more, they have less to gain from redistribution, and are more likely to adopt conservative values. There are good reasons to expect the beauty premium to be especially strong for non-incumbent candidates, about whom voters know less, and among less informed voters. Voters associate beauty with competence; so even if voters would claim to vote for the candidate who looks more competent, rather than the more beautiful candidate, this could reflect a "halo effect" from beauty to perceived competence.

\section{DISCUSSION OF PROS AND CONS}

Acquiring information is costly: it takes time and effort that could be used for other purposes. Therefore, people rely on various rules of thumb when making choices. This is a general pattern in life, but it may be especially pronounced in politics. In any big election, the likelihood of providing the pivotal vote is tiny for any given individual. This incentivizes voters to economize the acquisition of costly information, relying instead on easily-available information, like photos of candidates. As an example of how information is gained via visual cues, Princeton undergraduate and graduate students were asked to rate photos of American political candidates; it was found that inferences of competence from photos correctly predicted the outcomes of $72 \%$ of Senate races and $67 \%$ of House of Representatives races [4]. Candidate photos were also used to predict electoral outcomes in general elections in Germany, with more beautiful candidates winning more votes [5]. Another study showed that attractive candidates are more likely to be elected to non-partisan community partnership boards in the UK. These elections are considered low-information settings (i.e. candidates are not well known), to the extent that candidate photographs were included on the ballot to provide voters with more information about the candidates [6]. In Finland, which has a proportional system and personal vote, the effects of beauty and perceived competence and trustworthiness in intra-party competition were analyzed using official campaign photos of candidates representing four of the five biggest parties [1]. In the Finnish system, each voter has to choose one candidate to vote for and it is not possible to vote just for a party. The allocation of seats to different parties depends on their total number of votes, and seats are allocated within each party to those candidates who received the most votes. 
The main analysis in the Finnish study focused on non-incumbent candidates, as voters can be expected to know less about them, and would therefore be more likely to rely on information conveyed by candidate photos. While controlling for party popularity, district sizes, and the number of candidates that a party has in a district, a significant beauty premium was found: An increase of one standard deviation in the average beauty rating of a candidate, relative to other non-incumbent candidates on the same list, was associated with $20 \%$ more votes for the average non-incumbent parliamentary candidate, and $17 \%$ more votes for the average non-incumbent municipal candidate. Adding controls for education and occupation leaves the beauty premium virtually unchanged [1].

Another study analyzed between-party competition in one-member districts and showed that there is a beauty premium in Australian politics as well. According to the results, an increase of one standard deviation in a candidate's beauty is associated with an increase of 1.5 to 2 percentage points in the candidate's vote share. The analysis was based on candidate photos distributed in how-to-vote cards outside polling stations [7].

Importantly, for the study on Finnish non-incumbent candidates, only candidate evaluations collected from outside of Finland were used in the main analysis. Respondents were also asked to write the name of any candidate that they recognized. None of the respondents wrote a correct name for any of the candidates; the only Finnish politician who was named was a former president whose photo was not in the data set. This suggests that the results should not be distorted by unreported recognition of any of the candidates [1].

The Finnish study also compared the effects of beauty and perceived competence and trustworthiness. When all three traits are included simultaneously, only beauty has a statistically significant effect [1]. Therefore, it appears that there is a halo effect: Beautiful people are perceived more positively in character-based inferences such as perceived competence [8]. Figure 1 shows the estimated effects of beauty, perceived competence and perceived trustworthiness among female and male non-incumbent candidates in parliamentary elections. Although the point estimate of the beauty premium is slightly larger for female candidates, the gender difference is not statistically significant. As such, beauty appears to benefit women and men about equally. If only beauty, gender, and age are controlled for, the beauty premium for both male and female non-incumbent candidates increases somewhat, so that an increase of one standard deviation in the average beauty rating of a candidate, relative to other non-incumbent candidates on the same list, is associated with $23 \%$ more votes for the average non-incumbent candidate in parliamentary elections [1].

\section{Parliamentary versus municipal elections}

Parliamentary elections are associated with intense campaigning, and being a member of parliament is a full-time job. In contrast, municipal elections are associated with much less campaigning, and being a municipal council member is a side job. There are good reasons to expect that voters have much more information about electoral candidates in parliamentary elections than in municipal elections. Candidates in parliamentary elections have typically already served in municipal politics, which often serves as a stepping stone 


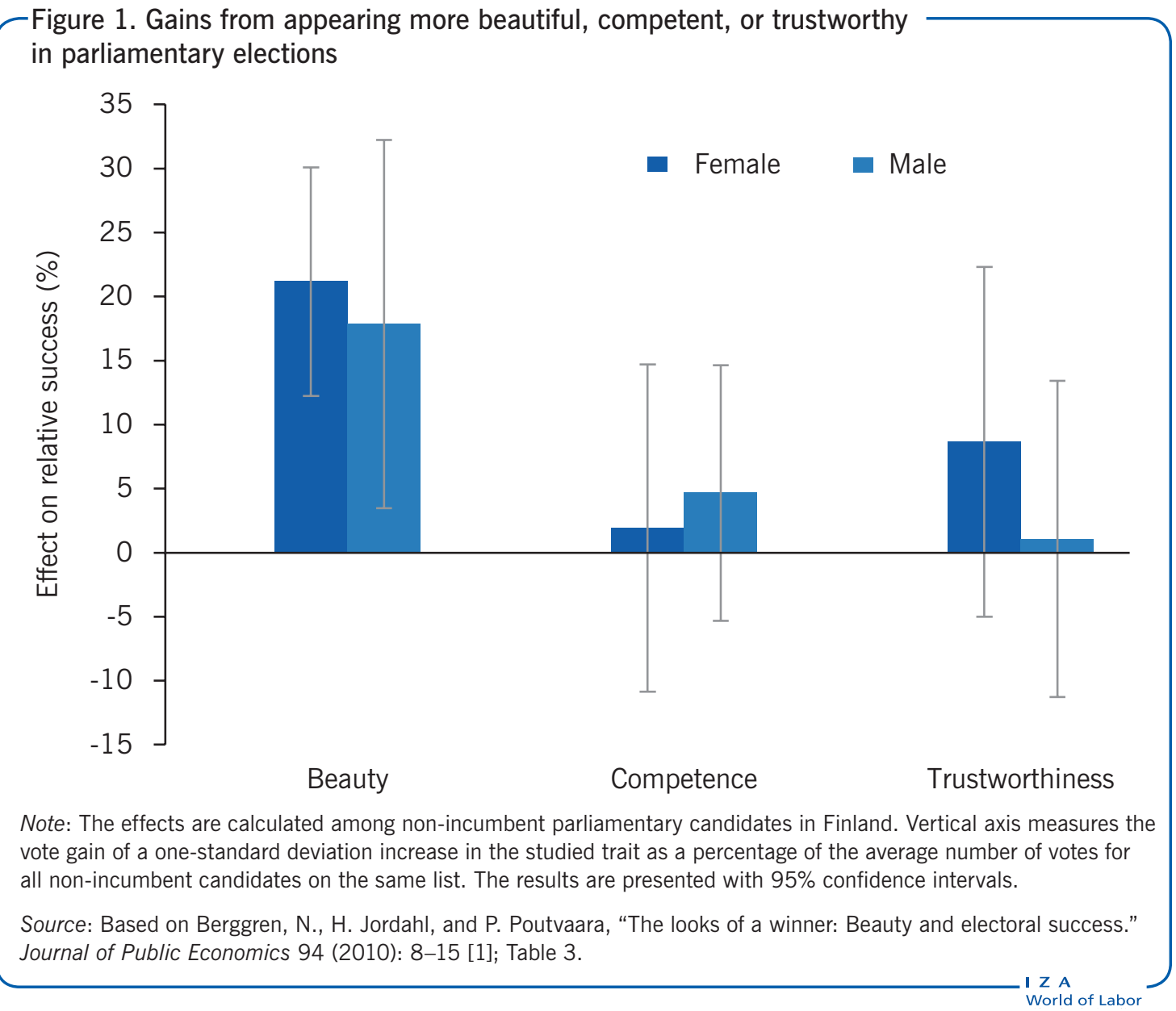

to national politics. Therefore, already at the candidate selection stage, parliamentary candidates should be better known than municipal candidates. Such differences can be expected to increase throughout the electoral campaign, as advertising is much more intense in parliamentary elections.

The Finnish study found that the gains from a candidate's good looks are only marginally smaller in municipal elections than in parliamentary elections. The estimated effect of perceived competence is somewhat larger for female candidates though and statistically significant at $10 \%$ level. Figure 2 shows that the point estimate of the beauty effect on women is somewhat larger, but, just as in parliamentary elections, the gender difference is not statistically significant [1].

To estimate how big an effect candidate appearance has on electoral outcomes, a hypothetical exercise was conducted. It was assumed that the beauty rating of all elected non-incumbent candidates was reduced by one standard deviation, and the beauty rating of the same number of unelected non-incumbent candidates who were closest to being elected was increased by one standard deviation. The hypothetical changes to the electoral outcomes were then calculated. Such a change would have replaced $12 \%$ of candidates elected in parliamentary election by more beautiful challengers. In the municipal election, the replacement rate would have been 5\% [1]. Although these 
Figure 2. Gains from appearing more beautiful, competent, or trustworthy in municipal elections

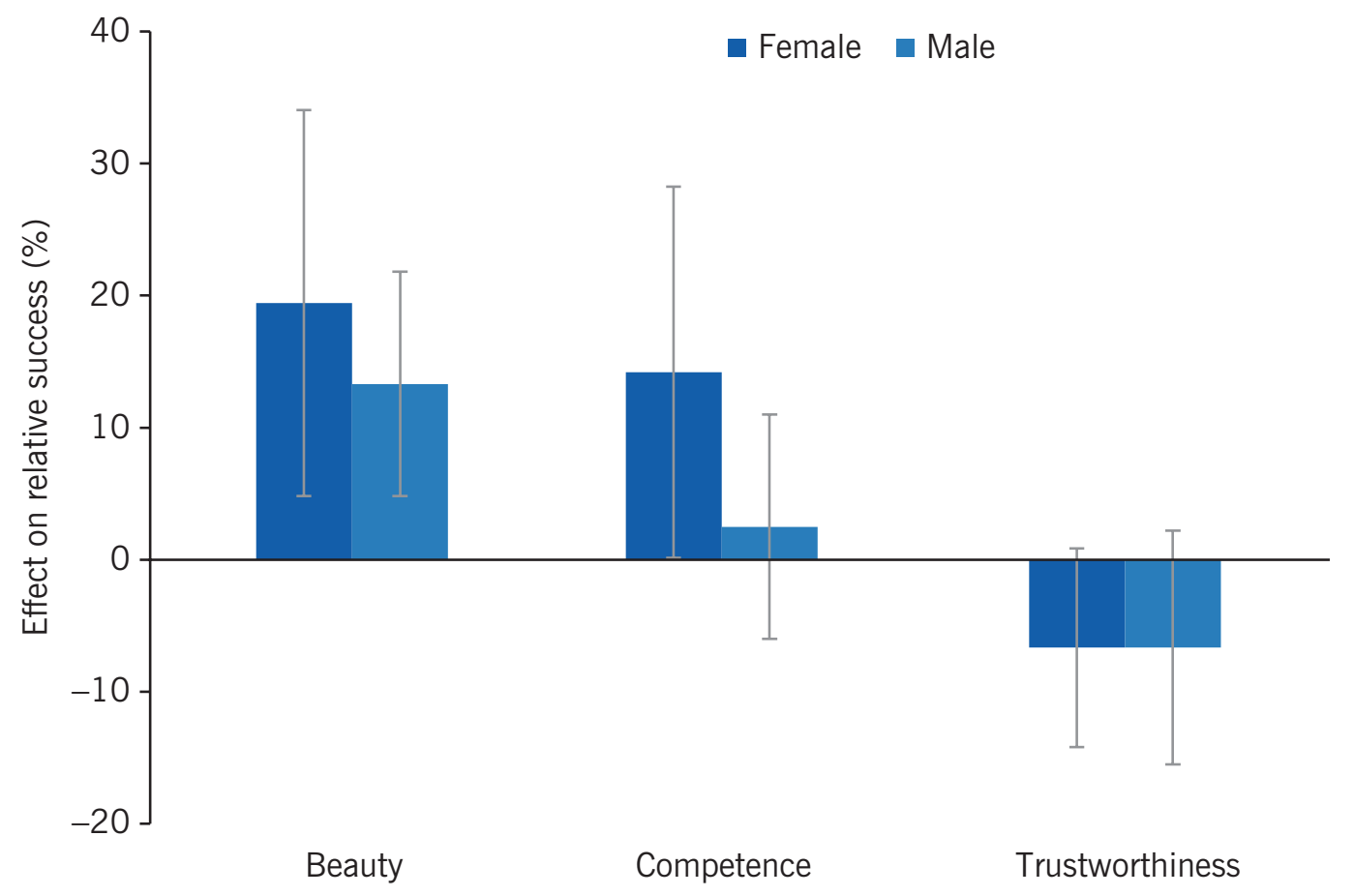

Note: The effects are calculated among non-incumbent municipal candidates in Finland. Vertical axis measures the vote gain of a one-standard deviation increase in the studied trait as a percentage of the average number of votes for all non-incumbent candidates on the same list. The results are presented with $95 \%$ confidence intervals.

Source: Based on Berggren, N., H. Jordahl, and P. Poutvaara, "The looks of a winner: Beauty and electoral success." Journal of Public Economics 94 (2010): 8-15 [1]; Table S4. Supplementary data available online at doi:10.1016/j. jpubeco.2009.11.002

numbers need to be viewed with caution, they suggest that candidate appearance can play an important role both in parliamentary and municipal elections, especially when candidates are close to the margin of being elected.

\section{Beauty and perceived competence are correlated}

Beauty and perceptions of competence, trustworthiness, likability and intelligence are all positively correlated. The correlation is largest between perceived competence and intelligence (correlation coefficient $0.65 ; 1$ would reflect perfect correlation). The correlation coefficient between beauty and perceived competence is 0.32 . Positive correlations are likely to reflect a halo effect: More beautiful candidates are evaluated more positively in other dimensions too. If all five traits are included as controls at the same time, the estimated beauty premium for Finnish parliamentary candidates remains almost unchanged at $18 \%$, which is statistically highly significant, while the estimated effects of perceptions of all other traits are rather small and statistically insignificant [1].

Using respondents from Finland, many of whom recognized many of the candidates shown in the study, gives a rather similar estimate on the effect of candidate beauty as when using respondents from other countries. This result holds whether candidates who 
were recognized by the Finnish respondents are excluded or not. However, the estimated effect of perceived competence becomes stronger for Finnish respondents, especially if recognized candidates are included, but also to a lesser degree if they are excluded. This suggests that unreported candidate recognition may distort evaluations, and provides an additional argument in favor of collecting appearance evaluations from a different country than that from which the candidate photos are collected [1].

\section{Beauty in the eyes of men and women}

Comparing evaluations of male and female candidates by male and female respondents reveals interesting differences. Male respondents give male candidates higher ratings of perceived competence and intelligence, while female candidates receive higher ratings for beauty, likability and trustworthiness. Female respondents, instead, give female candidates higher ratings than male candidates in every respect, although the difference in perceived intelligence is small and statistically insignificant. In general, male and female respondents evaluate male candidates rather similarly, with the only statistically significant difference being that male respondents find male candidates more beautiful than female respondents. Female respondents evaluate female candidates more positively overall than male respondents [1].

It has been claimed that it would be disadvantageous for female candidates to look too good. However, the Finnish study found no support for this hypothesis. Among both female and male candidates, there is a strong positive relationship between beauty and perceived competence, as well as between beauty and perceived intelligence. This effect is monotonic: Respondents give the highest competence and intelligence assessments, on average, to those candidates whom they find most handsome or beautiful.

\section{Beauty difference between political left and political right}

A more recent international study analyzed the political consequences of the beauty premium using evaluations of electoral candidates in Australia, Finland, and the US, as well as photos of all Members of the European Parliament (MEPs) [3]. As shown in Figure 3 , politicians on the right are more beautiful in all evaluated regions. This can be assumed to give the political right an advantage in elections. Such an advantage is expected to be especially strong among less informed voters, particularly if they rely on cues such as candidate appearance to determine their voting behavior. Evidence for such a conjecture is also provided by another US study in which an analysis showed that candidates who look more competent win more votes, especially among voters who are politically uninformed and watch a lot of television [9].

The difference in the average beauty ratings of politicians on the left and on the right cannot be explained by respondents' ideology. Respondents were asked whether they would support increasing redistribution in their country of residence and those supporting more redistribution were interpreted to represent the political left, while those against more redistribution the political right. Both respondents who were on the left and respondents who were on the right evaluated politicians representing political parties on the right to look better, on average, than politicians representing political parties on the left. The 
Figure 3. Beauty advantages for politicians on the right

\begin{tabular}{ll}
\hline & Beauty advantage (\%) \\
\hline Australia & 32 \\
EU & 25 \\
Finland & 41 \\
US & 14 \\
\hline
\end{tabular}

Note: "Beauty advantage" is defined as the difference between the average beauty rating of politicians on the right and the left, expressed as a percentage share of the standard deviation of all politicians' beauty ratings. Australia: candidates for the House of Representatives; EU: Members of the European Parliament; Finland: candidates in municipal and parliamentary elections; US: candidates in Senate and gubernatorial elections. Respondents evaluating Australian candidates were Australian; respondents evaluating MEPs were American; respondents evaluating Finnish candidates were all non-Finns; and respondents evaluating American candidates were predominantly European.

Source: Berggren, N., H. Jordahl and P. Poutvaara, "The right look: Conservative politicians look better and voters reward it." Journal of Public Economics 146 (2017): 79-86 [3]; Table 1.

difference cannot be explained by clothing style either, as the difference holds even when candidates being formally dressed (defined by wearing a tie for men and a blouse or suit for women) are analyzed separately from candidates not being formally dressed. In both groups, politicians on the right are evaluated to look better, on average [3].

\section{Beauty as a cue for ideology}

In addition to establishing that political parties on the right have a beauty advantage compared to parties on the left, the international study suggests an accompanying explanation [3]. It has been shown that there is a considerable beauty premium in the labor market [10]. Given that beautiful people earn more, it is in their self-interest to be less supportive of redistribution. As beautiful people are also treated better in social interactions, they are arguably more likely to view the world as a just place, thereby being more likely to adopt conservative values.

Against this background, the study suggests that voters are likely to use beauty as a cue for conservatism when they do not know much about candidates. That is, candidates who look better are more likely expected to be members of the political right. To test this prediction, evaluations on beauty and perceived ideology of MEPs and political candidates in the US were collected. Accordingly, more beautiful politicians were perceived to be further to the right. As another test, respondents were asked to guess the political bloc of Finnish political candidates. In general, politicians on the right were inferred to represent the political right more often than the political left, and politicians representing the political left were inferred to represent the political left more often than the political right. Thus, candidate ideology can, to a certain extent, be inferred from faces, at a much better rate than a random guess [3].

The strongest test of the hypothesis that voters use beauty as a cue for ideology comes from comparing the link between beauty and perceived ideology among politicians who de facto belong to the same bloc. When looking at politicians belonging to the political 
right, those who were more often inferred to represent the political right looked, on average, more beautiful than those who were incorrectly inferred to represent the political left. Among politicians belonging to the political left, those who were more often inferred, incorrectly, to represent the political right looked, on average, more beautiful than those who were, correctly, inferred to represent the political left [3]. In other words, beauty was used as a cue for being conservative.

To sum up: Uninformed people indeed appear to use beauty as a cue for conservative ideology when evaluating political candidates.

\section{The beauty gap in experimental elections}

An experimental study that mimicked an election provides additional evidence that the higher beauty premium on the right reflects a causal mechanism. In the experiment, 100 randomly selected photographs of Finnish candidates on the political left were matched with photos of 100 candidates on the right. The candidate photos were grouped into pairs of similar age and gender and respondents were asked to decide which candidate they would vote for. All 41 respondents were non-Finns residing outside of Finland, and the photographs were the only information about the candidates available to them. Candidates on the right were chosen more often by the majority of respondents from both the left and the right (being defined as those respondents who were in favor of and opposed to increasing redistribution, respectively). Candidates on the right received more votes in $60 \%$ of the experimental elections among respondents on the left, and in $72 \%$ of races among respondents on the right. In terms of vote shares, candidates on the right had an average vote share of $57 \%$ among respondents on the left and $66 \%$ among respondents on the right [3]. This confirms that voters on the right value beauty more than voters on the left do. Yet, voters on the left also tend to favor better-looking candidates.

Taken together, findings that politicians on the right are more beautiful and that voters on the right and on the left tend to favor better-looking candidates suggest that the role of beauty tilts political outcomes towards the right. The advantage for parties on the right arises among politically mobile voters who are willing to consider voting for a candidate representing either the political left or the political right.

\section{LIMITATIONS AND GAPS}

A major challenge in estimating the effects of good looks on electoral success is establishing the direction of causality. Political parties are more likely to attract more popular candidates in electoral districts in which they are stronger, both because they have a wider pool of supporters among whom to recruit candidates, and because being a candidate for a stronger party is more appealing, as it gives a higher chance of being elected. This could extend to being able to recruit more attractive candidates, meaning that in analyzing one-member electoral systems, there is a severe risk of reverse causality from electoral success to candidate appearance.

Importantly, the studies on Finnish non-incumbent candidates avoid this problem by analyzing within-party competition in a proportional electoral system (see [1] and [3]). As 
voters have to choose a candidate from a party list, it is possible to analyze within-party competition between candidates belonging to the same party in the same district, thereby avoiding confounding factors that could arise from differences in party popularity. This relative electoral success variable controls for differences in party popularity by analyzing how popular candidates are relative to other candidates on the same list. It also allows for the separate analysis of non-incumbents, the group for which beauty can be expected to be most important.

There are different pieces of evidence suggesting that appearance plays a causal role in explaining electoral success. As it was found that candidates who look more competent win more votes, especially among voters who are politically uninformed and watch a lot of television, it seems that the effects of appearance cannot just reflect true unobserved abilities [9]. Even stronger evidence comes from a field experiment in which the treatment group received ballots that included candidate photographs, while the control group did not receive photographs. It turned out that voters in the treatment group were considerably more likely to vote for a candidate with an appearance advantage [11]. It is important to note that although voters seem to use beauty as a cue for candidate ability and ideology, it remains an open question whether the use of appearance helps voters to make better decisions. The possibility remains that voters are instead blinded by beauty and therefore make worse decisions at the ballot box.

\section{SUMMARY AND POLICY ADVICE}

Benefits from good looks in politics appear to be universal. This should not come as a surprise, given the strong evidence for beauty premium in labor markets [12]. There are even reasons to expect that looks could matter more in politics than in the labor market in general. An employer may interview several job applicants, and is certain that he or she can make the final choice about whom to hire. By contrast, only a small minority of voters has the chance to talk with political candidates during an electoral campaign, and it is very unlikely that an individual voter will be pivotal in any political election of a reasonable size. As a result, voters can be expected to resort to various heuristics to minimize their costs of information acquisition, by voting for the better-looking candidate. The evidence supports this idea that voters use candidate appearance as a cue for candidate ability and ideology. Moreover, candidates on the right look, on average, better than candidates on the left, which gives them an electoral advantage [3].

However, the results do not imply that political parties should move to replace their less attractive established politicians with more beautiful but less experienced candidates in an attempt to maximize their electoral success. The incumbency advantage is an orderof-magnitude larger than the beauty premium [1]. Beauty is neither a necessary nor a sufficient condition for electoral success. However, it can make a difference in a tight race, particularly for those running near the electoral margin. In a close election, such marginal effects in several districts might in fact determine which party bloc achieves majority. Therefore, a political party intent on maximizing its electoral success would be well advised to pay attention to how its candidates look. The fact that parties use candidate photos widely in electoral campaigns suggests that they are well aware of the importance of images. For voters, the main advice is caution: To pause for a moment to reflect to what extent one's voting decision is influenced by candidate looks. 


\section{Acknowledgments}

The author thanks an anonymous referee and the IZA World of Labor editors for helpful suggestions on earlier drafts. The author is also grateful to Niclas Berggren and Henrik Jordahl for excellent comments. The key results in this text were derived in joint papers with Niclas Berggren and Henrik Jordahl [1], [3].

\section{Competing interests}

The IZA World of Labor project is committed to the IZA Guiding Principles of Research Integrity. The author declares to have observed these principles.

(C) Panu Poutvaara 


\section{REFERENCES}

\section{Further reading}

Antonakis, J., and O. Dalgas. “Predicting elections: Child's play!” Science 323 (2009): 1183.

Poutvaara, P., H. Jordahl and N. Berggren, "Faces of politicians: Babyfacedness predicts inferred competence but not electoral success." Journal of Experimental Social Psychology 45 (2009): 1132-1135.

Praino, R., D. Stockemer, and J. Ratis, "Looking good or looking competent? Physical appearance and electoral success in the 2008 congressional elections." American Politics Research 42 (2014): 1096-1117.

\section{Key references}

[1] Berggren, N., H. Jordahl, and P. Poutvaara. "The looks of a winner: Beauty and electoral success." Journal of Public Economics 94:1-2(2010): 8-15.

[2] Poutvaara, P. "Facial appearance and leadership: An overview and challenges for new research." The Leadership Quarterly 25:5 (2014): 801-804.

[3] Berggren, N., H. Jordahl, and P. Poutvaara. "The right look: Conservative politicians look better and voters reward it." Journal of Public Economics 146 (2017): 79-86.

[4] Todorov, A., A. N. Mandisodza, A. Goren, and C. C. Hall. "Inferences of competence from faces predict election outcomes." Science 308:5278 (2005): 1623-1626.

[5] Rosar, U., M. Klein, and T. Beckers. "The frog pond beauty contest: Physical attractiveness and electoral success of the constituency candidates at the North Rhine-Westphalia state election 2005." European Journal of Political Research 47:1 (2008): 64-79.

[6] Banducci, S. A., J. A. Karp, M. Thrasher, and C. Rallings. "Ballot photographs as cues in low-information elections." Political Psychology 29:6 (2008): 903-917.

[7] King, A., and A. Leigh. "Beautiful politicians." Kyklos 62:4 (2009): 579-593.

[8] Verhulst, B., M. Lodge, and H. Lavine. "The attractiveness halo: Why some candidates are perceived more favorably than others." Journal of Nonverbal Behavior 34:2 (2010): 111-117.

[9] Lenz, G. S. and C. Lawson. "Looking the part: Television leads less informed citizens to vote based on candidates' appearance." American Journal of Political Science 55:3 (2011): 574-589.

[10] Hamermesh, D. S., and J. E. Biddle. "Beauty and the labor market." American Economic Review 84:5 (1994): 1174-1194.

[11] Ahler, D. J., J. Citrin, M. C. Dougal, and G. S. Lenz. "Face value? Experimental evidence that candidate appearance influences electoral choice." Political Behavior 39:1 (2017): 77-102.

[12] Hamermesh, D. S. Beauty Pays: Why Attractive People Are More Successful. Princeton, NJ: Princeton University Press, 2011.

\section{Online extras}

The full reference list for this article is available from:

http://wol.iza.org/articles/how-do-candidates-looks-affect-their-election-chances

View the evidence map for this article:

http://wol.iza.org/articles/how-do-candidates-looks-affect-their-election-chances/map 